\title{
Fracture of endodontic instruments - Part 1: Literature review on factors that influence instrument breakage
}

\author{
SADJ November 2020, Vol. 75 No. 10 p553 - p563
}

M Pillay', M Vorster², PJ van der Vyver ${ }^{3}$

\section{INTRODUCTION}

Instrument fracture is a serious complication during endodontic treatment of teeth, having an adverse effect on the outcome of the nickel titanium (NiTi) treatment, especially if the fracture prevents apical access to the infected root canal. Despite the advent of NiTi files, the risk of fracture during the endodontic preparation of root canals, especially in severely curved canals, remains a serious concern. The fracture of NiTi files during preparation may result in a compromised prognosis for the tooth. In the presence of periapical lesions, instrument fracture may reduce the chances of successful healing. ${ }^{1}$

It is noticed clinically that when an instrument fractures in a root canal system, it is often associated with incomplete root canal obturation, ineffective coronal seal or poor definitive restorations (Figures 1 and 2). This further leads to micro-organisms penetrating the root canal system, indicating the development of a periapical lesion and treatment failure. ${ }^{2,3}$

Fractured endodontic instruments may include endodontic files, Gates-Glidden burs, lateral or finger spreaders or spiral fillers manufactured from stainless steel, NiTi or carbon steel. ${ }^{1}$ According to a limited number of studies, the fracture incidence of rotary $\mathrm{NiTi}$ files ranges from 0.4 to $5 \%, 4,5$ with the higher percentage representing fractures in molar teeth only. ${ }^{4}$ In a majority of cases instrument fracture results from incorrect use or overuse, occurring most frequently in the apical third of the root canal. ${ }^{6}$

\section{Author affiliations:}

1. Maheshan Pillay: BChD (Pret), Dip Odont (Endo), MSc (Pret), Department of Odontology, School of Dentistry, University of Pretoria, Pretoria, South Africa.

ORCID Number: 0000-0003-1794-7834

2. Martin Vorster: BChD, PG Dip Dent (Endo), MSc (Pret), Department of Odontology, School of Dentistry, University of Pretoria, Pretoria, South Africa.

ORCID Number: 0000-0003-4470-1530

3. Peet J van der Vyver: BChD, PG Dip Dent (Endo), PG Dip Dent (Aesthet Dent), MSc, PhD (Pret), Department of Odontology, School of Dentistry, University of Pretoria, Pretoria, South Africa. ORCID Number: 0000-0003-1951-6042

Corresponding author: Martin Vorster

Department of Odontology, School of Dentistry, University of Pretoria

Gauteng, South Africa.

Email: martin.vorster@up.ac.za

Author contributions:

1. Maheshan Pillay: Scientific writing and editing - $40 \%$

2. Martin Vorster: Scientific writing and editing - $30 \%$

3. Peet $\mathbf{J}$ van der Vyver: Scientific writing and editing - $30 \%$
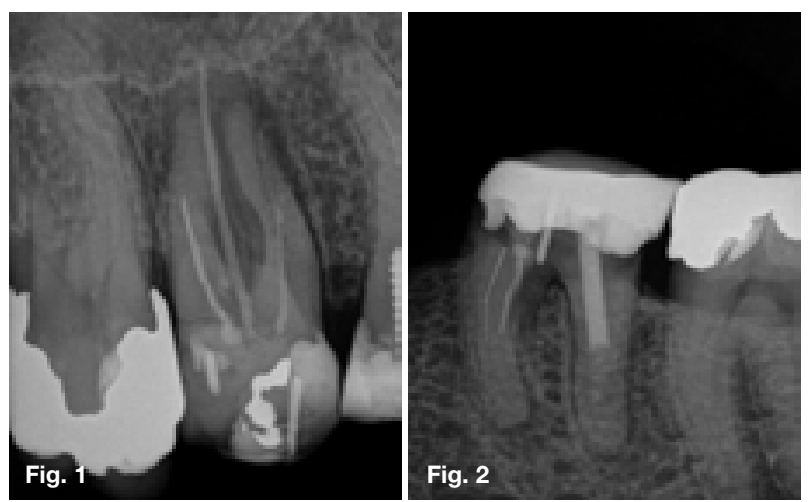

Figure 1. Periapical radiograph of a maxillary right first molar with a fractured instrument in the disto-buccal root canal system. Note the poor canal preparation and obturation in the palatal and mesio-buccal root canal systems that resulted in extensive periapical pathology.

Figure 2. Periapical radiograph of a mandibular left first molar with several fractured instruments in the mesio-buccal and mesio-lingual root canal systems. Note the absence of root canal treatment in the distal root before post placement, with an inadequate coronal restoration with extensive decay leading to coronal leakage and periapical infection.

Rotary NiTi files are known to fracture without any visible signs of deformation and potential fracture, compared to the evident warning signs seen in traditional stainless steel files.

New studies indicate that instrument fracture has many variables, the most crucial being the clinician's skill. ${ }^{8}$ A study by Arens et al. ${ }^{9}$ reports that $0.9 \%$ of brand-new $\mathrm{NiTi}$ instruments fractured during their first use, conceivably due to a manufacturing defect or misuse.

As a result of their improved designs and cross-sections, endodontic instruments subjected to torsional and flexural loads may have an altered resistance to fracture..$^{10,11}$ The low tensile strength and yield of NiTi instruments (compared to stainless steel instruments) results in a higher fracture risk at lower loads. ${ }^{12}$ Fracture incidence of rotary NiTi instruments is significantly influenced by the clinician's proficiency with instruments and the number of uses of the instrument. 8,13

The success of endodontic treatment may be influenced by the fracture of NiTi files. The last decade has seen instrument manufacturers make modifications to $\mathrm{NiTi}$ alloy to reduce the incidence of instrument fracture. The removal of a fractured endodontic file is technically challenging and time intensive, hence it is crucial to limit the probability of instrument fracture. ${ }^{14}$ 
There are conflicting results from studies on the overall outcomes and successes of endodontic treatment when a fractured endodontic instrument is left within the root canal. A study by Spili et al. ${ }^{1}$ investigated the impact of instrument fracture on the outcome of endodontic treatment, and found that in certain cases whena fractured endodontic instrument remained in the tooth, there was no significant difference in the outcome of non-surgical root canal treatment and retreatment. However, the presence of a pre-operative periapical lesion was a more clinically significant prognostic indicator than a fractured instrument per se.

The fracture of endodontic rotary instruments can be broadly classified into two types: fractures due to cyclic fatigue and fractures due to torsional fatigue. ${ }^{15}$ Fatigue has been implicated as one of the key reasons for endodontic instrument fracture. ${ }^{16,17}$

\section{Cyclic fatigue}

Cyclic fatigue is a major cause of separation of $\mathrm{NiTi}$ rotary instruments during clinical use. ${ }^{16}$ Cyclic fatigue occurs because of tension-compression stress cycles at the point of maximum flexure. ${ }^{18}$ Cyclic fatigue resistance is measured either by the number of cycles to fracture or the time until fracture. ${ }^{19}$ The repeated extension and compression of an instrument in a curved canal may cause work hardening of the alloy, thereby creating cyclic fatigue and increased fracture risk. ${ }^{20}$

Cyclic fatigue fracture occurs fundamentally as a result of overuse of the NiTi alloy. Other potential factors that contribute to metal alloy fatigue include changes due to thermal expansion and contraction, as well as corrosion. ${ }^{21}$ Factors such as the alloy, kinematics, metallurgical properties and operational settings of the instrument contribute to cyclic fatigue resistance. ${ }^{22}$

New concepts and designs in NiTi alloys, including thermomechanical improvements, have improved their cyclic fatigue resistance. ${ }^{23}$ The cyclic fatigue resistance of a $\mathrm{NiTi}$ instrument is influenced by the metal mass of the file at the point of maximum stress ${ }^{24}$ as well as the anatomy of the root canal; the greater the canal curvature, the greater the cyclic fatigue. ${ }^{25}$ The cyclic fatigue resistance of rotary $\mathrm{NiTi}$ files decreases with increasing file diameters. ${ }^{8}$

\section{Torsional fracture}

Torsional fracture occurs when part of the instrument binds to the canal while the shank continues to rotate. ${ }^{26}$ The fracture occurs when the elastic limit of the alloy is exceeded. Instruments that fracture as a result of torsional stress exhibit signs of deformation such as twisting, unwinding and straightening. ${ }^{21}$

Instrument manufacturing processes, designs and protocols can improve resistance to cyclic stress, but not to torsional stress since it is more dependent on the operator. ${ }^{27}$ Torsional stresses are rapidly increased with the use of a large tapered endodontic instrument in a low-tapered, unprepared root canal. ${ }^{28}$ There is a high incidence of torsional fracture during the preparation of complex constricted root canals where the instrument is susceptible to increased torsional loads. ${ }^{15}$

Numerous studies have stated that $\mathrm{NiTi}$ instruments with lower metal mass and small cross-sectional areas usually have lower torsional strengths. ${ }^{29-31}$ Conventional $\mathrm{NiTi}$ files have a higher fracture risk when exposed to torsional stresses at lower cyclic fatigue levels. NiTi instruments which have been previously used have a high fracture risk as a result of their reduced torsional stress resistance.

\section{Factors influencing fracture resistance}

\section{Design and manufacture}

Instrument design and cross-section are crucial factors in the resistance to fracture when the instrument is subjected to torsional and flexural loads. ${ }^{10} \mathrm{NiTi}$ instruments with a triangular cross-sectional geometry have been shown to possess better fatigue resistance than instruments with a square cross-section. ${ }^{32}$

Many methods such as heat treatment, electropolishing and alterations of the cross-section of files have been developed to prevent the fracture of NiTi rotary file instruments. ${ }^{33}$ The use of heat treatment to transform the alloy into an altered crystalline phase structure is a cost-effective method of manufacturing NiTi instruments with superior fatigue resistance and flexibility. ${ }^{34}$

M-Wire is composed of 508 Nitinol, thermomechanically treated under specific tensile stresses and temperatures. ${ }^{35}$ M-Wire instruments are manufactured by transforming $\mathrm{NiTi}$ wire in the austenite phase into the R-phase, a transitional phase during the transformation of martensite to austenite by heating and cooling. ${ }^{36}$

A study of the metallurgical characterisation of M-Wire found that it contains deformed and twinned martensite, R-Phase and austenite crystalline phases. The deformed and micro-twinned martensite is responsible for the increased strength of the M-Wire compared to the conventional super-elastic wire without martensitic structure. ${ }^{37}$

Numerous metallurgical laboratory techniques have demonstrated that M-Wire contains the austenite phase with small amounts of martensite and R-Phase, thus rendering $\mathrm{M}$-Wire more flexible and resistant to cyclic fatigue than conventional NiTi files. ${ }^{38-40}$

Endodontic instruments manufactured with M-Wire exhibited better cyclic fatigue resistance than conventional $\mathrm{NiTi}$ alloys. ${ }^{38}$ The increased flexibility of M-Wire can be attributed to the presence of the martensitic phase and R-Phase. The elastic moduli of martensite and R-Phase have been reported to be lower than that of austenite. ${ }^{19}$

A study by Bonessio et al. ${ }^{41}$ found that M-Wire instruments demonstrated higher flexibility than conventional $\mathrm{NiTi}$, which can prevent premature fracture of the instrument if there is excessive bending during rotation.

M-Wire was shown to be more flexible and harder than conventional NiTi wire, with superior physical and mechanical properties. ${ }^{35,42}$ 
In 2010, rotary NiTi instruments were developed using a proprietary thermal process called Controlled Memory (CM) technology. ${ }^{43}$ CM-Wire (DS Dental, Johnson City, $\mathrm{TN}$ ) is an alloy manufactured using an unique thermomechanical treatment that controls the memory of the instrument, resulting in superior flexibility without the shape memory of conventional NiTi instruments. ${ }^{44}$

Studies have demonstrated that instruments manufactured with $\mathrm{CM}$ technology possess superior cyclic fatigue resistance and flexibility to conventional NiTi instruments, which can be attributed to their martensitic state. ${ }^{45,46}$

In a study comparing the cyclic fatigue properties of Proflexendo (Nexden, Houston, TX, USA), manufactured using CM-Wire, to Profile Vortex (Dentsply Tulsa Dental, Tulsa, OK, USA) and ProTaper Universal (Dentsply Sirona, Ballaigues, Switzerland) manufactured with M-Wire, the Proflexendo exhibited significantly greater cyclic fatigue resistance. The Proflexendo demonstrated almost $500 \%$ more resistance to cyclic fatigue than the M-Wire instruments. ${ }^{47}$

Galal${ }^{48}$ evaluated the metallurgical effect on the mechanical behaviour of $\mathrm{CM}$ files, M-Wire files and R-phase files using finite element analysis. The study showed CM files to be more flexible and resistant to torsional stresses than M-Wire files.

A study by Shen et al. ${ }^{49}$ reports that the triangular and square design of a $\mathrm{NiTi}$ instrument made from $\mathrm{CM}$ Wire demonstrated a significantly increased cyclic fatigue resistance. Thus, the design of the instrument should be considered, as it is an important factor in the fatigue life of an instrument.

The distinctive gold appearance of WaveOne Gold (Dentsply Sirona) endodontic instruments is due to the heat treatment technology applied post-manufacture. The raw $\mathrm{NiTi}$ is heated and slowly cooled, a process which - the manufacturer claims - improves the strength and flexibility of the instruments. ${ }^{50}$

The heat treatment modifies the transformation temperatures (austenitic start and austenitic finish), resulting in increased strength and flexibility of the instrument. ${ }^{51}$ The proprietary heat treatment post-manufacture results in a two-stage Austenite- $R$ Phase-Martensite transformation, creating an austenitic matrix with finely dispersed $\mathrm{Ti}_{3} \mathrm{Ni}_{4}$ precipitates.

The manufacturer claims that this process improves the flexibility and strength of gold wire instruments. ${ }^{50}$ WaveOne Gold, which is developed with post-machining heat treatment, exhibits greater flexibility and higher fatigue resistance than conventional $\mathrm{NiTi}$ and $\mathrm{M}$-Wire. ${ }^{52}$

\section{Operator experience}

Operator experience is a factor that cannot be disregarded in the incidence of instrument fractures. Yared et al. $^{53}$ and Yared and Kulkarini ${ }^{54}$ conclude that there is a greater incidence of file fracture with inexperienced and less-informed clinicians. This conclusion implies that with continued use of rotary instruments, a clinician develops an improved tactile awareness, allowing for the detection of an increase in the torsional resistance. The skill of the operator is a key factor in instrument fracture when instrument speed, sequence and canal morphology are kept constant. ${ }^{55}$

Numerous factors such as the design and manufacturing process, operator experience, number of uses, instrumentation technique and root canal anatomy have been implicated in the fracture of endodontic instruments. ${ }^{56}$

There is a perception that NiTi instruments fracture more often than stainless steel instruments. However, the fracture incidence is comparable when NiTi files are used injudiciously. Pre-emptive measures such as good technique, the experience of the clinician, case selection and limiting file re-use have been demonstrated to reduce the incidence of fractures. ${ }^{21}$

In numerous cases, the fracture of rotary $\mathrm{NiTi}$ endodontic instruments occurs as a result of excessive or improper use, ${ }^{15,57}$ highlighting the importance of education and training in rotary $\mathrm{NiTi}$ instrument use. , $^{6,58}$ A study by Mandel et al. ${ }^{56}$ evaluated the influence of the operator on ProFile (Dentsply Sirona) rotary $\mathrm{NiTi}$ instrument fracture. The results show that there were more file fractures during the initial 'learning' phase than in the 'application' phase. This highlights the necessity of proper training and education to establish competence in using the different NiTi file systems.

\section{Number of uses}

The most crucial factor leading to the fracture of an instrument is metal fatigue, representative of the number of cycles an instrument can resist under a certain load. ${ }^{27}$ The risk of instrument fracture is low when an experienced endodontist uses a new instrument. Re-using an instrument increases the risk of file separation. If the engine file is treated as a single-use file, the number of file fractures is low. ${ }^{59}$

In 2006, Plotino et al. ${ }^{60}$ reported a significant reduction in cyclic fatigue resistance between a new and a used file. The study also demonstrated that rotary instruments may be safely used multiple times; however, it must be noted that the instruments were operated by an experienced endodontist.

There are a few studies which suggest that rotary instruments can be re-used in up to ten canals. ${ }^{54}$ Other studies suggest that in certain cases such as complex, severely curved and calcified canals, the instruments should be selectively discarded after a single use. ${ }^{25,61}$ Arens et al. ${ }^{62}$ report a low fracture incidence rate of $0.9 \%$ in 786 new rotary $\mathrm{NiTi}$ instruments, which had only been used once in predominantly difficult cases in an endodontic practice.

It is recommended that endodontic instruments are used once only to reduce the chances of instrument fracture due to cyclic fatigue and eliminate cross-contamination. Another reason is the impossibility of ensuring complete cleaning and sterilisation of instruments, hence the possible presence of prion protein. ${ }^{63}$ 


\section{Root canal anatomy}

The success of endodontic therapy depends on thorough chemical and mechanical disinfection of the canals and the complete three-dimensional obturation of the root canal system. Knowledge of the anatomy of the root canal system is essential, ${ }^{64}$ as its complicated individuality has a profound influence on the cyclic fatigue that instruments experience. ${ }^{30}$

Canal curvature is a crucial factor that affects instrument separation, with severe curvatures exerting greater stresses on instruments. An increase in the severity of the curve radius and angle around which an instrument rotates will reduce the lifespan of the instrument. ${ }^{65}$

The variable anatomy of C-shaped canal systems may lead to challenges in debridement and obturation of the canals. ${ }^{31}$ Canal geometry (e.g. angle, cross-sectional diameter and radius of the curvature) has an effect on the extent of stress an instrument experiences. ${ }^{66}$

\section{Irrigation and lubricants}

The success of endodontic treatment is based on effective shaping and disinfection of canals followed by three-dimensional obturation of the root canal system. ${ }^{67}$ Mechanical instrumentation of root canal systems alone cannot effectively disinfect them, regardless of the instruments used.

Sodium hypochlorite $(\mathrm{NaOCl})$ can cause corrosion of $\mathrm{NiTi}$ instruments by removing nickel from the surface, causing micropitting. ${ }^{68}$ It is postulated that microstructural defects can create areas of crack formation and stress concentrations, leading to weakening of the instrument surface. ${ }^{69}$

A study by Yguel-Henry and Von Stebut ${ }^{70}$ evaluating the effect of lubrication on the cutting efficiency of K-Files and Hedstrom files shows that $2.5 \% \mathrm{NaOCl}$ and tapwater solutions gave greater cutting efficiency than dry conditions. Peters et al. ${ }^{71}$ evaluated the effects of lubrication on torque-generated simulated rotary root canal instrumentation using ProFile and ProTaper (Dentsply Sirona) instruments.

The results indicate that a paste type lubricant is less effective than aqueous solutions, showing undesirable effects when used with U-shaped cross-sectioned rotary instruments. A reduction in torque and force was observed when lubrication with aqueous solutions was used in root canals.

A 2006 study by Berutti et al. ${ }^{72}$ concludes that when $\mathrm{NiTi}$ rotary instruments are used in conjunction with $\mathrm{NaOCl}$ solutions in pulp chambers of teeth restored with alloys or metals possessing different electrochemical nobility values, galvanic corrosion can occur. This phenomenon may lead to pitting and crack formation, altering the integrity of the instrument and resulting in decreased resistance to fracture as a result of cyclic fatigue.

A study by Uslu et al. ${ }^{73}$ evaluated the effect of $\mathrm{NaOCl}$ and ethylenediaminetetraacetic acid (EDTA) solutions on the cyclic fatigue resistance of WaveOne (Dentsply Sirona and WaveOne Gold NiTi reciprocating files. The study showed that exposing WaveOne and WaveOne Gold files to $\mathrm{NaOCl}$ and EDTA solutions did not influence the cyclic fatigue resistance of the files.

\section{Electrical endodontic motors}

The type of electrical endodontic motor plays an influential role in the outcome achieved with endodontic instruments. Mechanical limitations of electric motors arise when converting the direction of rotation, resulting in acceleration and deceleration in both directions. It is crucial to select an appropriate electric motor for each type of file system. ${ }^{30}$

Low-torque or controlled-torque endodontic motors capable of individually adjusted torque limits for individual files reduce the risk of instrument fracture by keeping the file working below the limit of file elasticity, without exceeding the file-specific torque limit.

The auto-reverse function is a great safety feature; however, a certain amount of force is required to stop the rotation of the instrument, disengage it from the initial path and rotate it in the opposing direction. This force is stored within the instrument memory; hence with repeated activations of the auto-reverse function, more memory is stored, resulting in a reduction in the lifespan of the instrument. ${ }^{74}$

High-torque motors increase the risk of instrument fracture as the file-specific torque limit is often exceeded. The use of low-torque instrumentation demonstrated an increase in operators' tactile sensation and mental awareness of rotary instrumentation. ${ }^{75}$

\section{Continuous rotary motion}

The biggest challenge in using rotary NiTi instruments has been separating files during use, which can be attributed to their use in continuous rotation. ${ }^{76}$ Studies have demonstrated the advantages of NiTi rotary instruments over stainless steel hand instruments. Such advantages include improved preservation of the shape and curvature of the original canal anatomy, fewer catastrophic errors and reduced treatment time..$^{5,77}$

A study by Gabel et al. ${ }^{78}$ demonstrates that the risk of instrument distortion and separation is four times greater at a rotational speed of $333.33 \mathrm{rpm}$ than at a speed of $167.67 \mathrm{rpm}$. The risk of instrument fracture is reduced at lower rotational speeds; conversely, there is increased risk at higher rotational speeds.

The advent of rotary $\mathrm{NiTi}$ endodontic instruments has improved the efficiency of endodontic treatment with regard to accuracy, risk reduction and procedural time. ${ }^{13}$

A study by Da Frota et al. ${ }^{79}$ found that torsional resistance and cyclic fatigue were lower for instruments from continuous rotary systems than for those from reciprocating systems during instrumentation, irrespective of axial displacement. 


\section{Reciprocation motion}

Reciprocating motion has been used for many years in endodontics. ${ }^{80}$ It can be defined as a repetitive backward-and-forward (clockwise (CW) / counter-clockwise (CCW)) movement which can be applied to endodontic instruments, or as an oscillating motion in which an instrument rotates in one direction, reverses direction, and then completes a full rotary cycle. ${ }^{81}$

In reciprocal motion, the degree of rotation differs in the CW and CCW directions. There is a higher degree of rotation in the CCW direction, which is the cutting direction, allowing for the progression of the instrument in the canal and dentine removal. There is a smaller degree of rotation in the $\mathrm{CW}$ direction, allowing for the instrument to unlock and safely move through the canal, hence reducing the risk of instrument separation. ${ }^{82}$

In reciprocating motion there is reduced risk of torsional fracture, which can be attributed to the angle of the CCW rotation which is intended to be smaller than the elastic limit of the instrument. ${ }^{34}$ The key advantage of reciprocal motion is the reduced incidence of endodon tic mishaps through file separation, which can be attributed to avoiding constant dentinal over engagement. This movement minimises flexural and torsional stresses, improves canal-centring ability and decreases the taper lock of the file in the canal. ${ }^{83}$

In 2008, Yared ${ }^{84}$ stated that a root canal can be efficiently shaped with a single file used in a forward reciprocating motion. The technique involved the use of a single 08 K-File hand instrument and one F2 ProTaper Universal $\mathrm{NiTi}$ rotary instrument in reciprocating motion. This technique also increases the cyclic fatigue resistance of the file, reduces the number of instruments required and minimises possible contamination. An extended lifespan was recorded for NiTi instruments used in reciprocating motion. ${ }^{30}$

A study by Hamid et al. ${ }^{77}$ in a student clinic setting found $\mathrm{NiTi}$ reciprocating instruments to be superior to hybrid hand/NiTi rotary instruments in the reduction of treatment time, procedural errors and fracture incidence and the improvement of obturation length and taper. Shenouda et al. ${ }^{85}$ evaluated the fracture resistance of WaveOne Primary, ProTaper Universal F2 and One Shape files. The results show the One Shape file to possess a significantly greater fracture resistance than the WaveOne Primary and ProTaper Universal F2 files.

It is recommended that single-file reciprocating instruments are used in only two or three root canals, depending on the complexity of the canal anatomy. Hence, the cyclic fatigue test for reciprocating instruments is vital. ${ }^{86}$ In this study, the cyclic fatigue resistance to fracture of the WaveOne Gold and One Curve file systems were compared. The influence of glide path preparation prior to final canal instrumentation on the fracture rate and preparation times were evaluated and compared between the two systems. Final canal preparation times with the Primary WaveOne Gold and One Curve were also recorded.
The endurance limit of NiTi files may be defined as the level of torsional stress a file may be subjected to over infinite cycles without failure. ${ }^{87}$ Torsional deformation develops on the axis of the file each time the file cuts dentine in a root canal in a rotary motion. There are no structural changes, provided the torsional deformation does not exceed the limits of plastic deformation. However, if the repeated torsional deformation is accrued and exceeds the endurance limits, the instru ment will fracture due to torsional fatigue.

This mechanism of stress is supplementary to the cyclic fatigue that is created within a curved root canal. Partial or asymmetrical reciprocation is the movement where the angle of rotation is limited in the cutting verse under the endurance limit of the instrument in which the angle of rotation is higher in the cutting verse than that of the angle of rotation in the opposite noncutting verse. ${ }^{88}$

Reciprocation offers many advantages over continuous rotation, such as a reduction of torsional and flexural stress on the instrument, reduced incidence of instruments binding to the canal walls, decreased risk of fracture and a reduction in the number of cycles during preparation of the root canal. ${ }^{89}$ A study by Rubio et al. ${ }^{90}$ shows that file systems with Gold-Wire alloys and reciprocating motion offer better resistance to cyclic fatigue than most of the continuous rotation systems evaluated in the study.

In 2010, You et al. ${ }^{91}$ analysed the lifespans of $\mathrm{NiTi}$ rotary instruments during preparation of extracted molars with curved root canals in continuous rotation and reciprocating motions. A sequence of ProTaper Universal SX, S1, S2, F1 and F2 files (Dentsply Sirona) were used in continuous rotation, while a ProTaper Universal F2 instrument was used in reciprocating motion. The study reports an extended lifespan for the ProTaper Universal F2 instrument used in reciprocating motion, which was safely negotiated to working length of the canals at least six times.

A literature review by Ferreira et al. ${ }^{92}$ finds the majority of studies suggest that reciprocating motion improves cyclic fatigue resistance better than continuous rotation, independent of other factors such as NiTi instrument design, the angle of curvature of the artificial canal and the speed of rotation. Kim et al. ${ }^{30}$ compared the Reciproc and WaveOne reciprocating files with the ProTaper Universal F2 file in continuous rotation mode.

The results show that both reciprocating file systems demonstrate a significantly higher torsional and cyclic fatigue resistance than the ProTaper Universal F2 file. Topçuoglu et al. ${ }^{93}$ determined that the Primary WaveOne Gold instrument exhibited greater cyclic fatigue resistance than the Primary WaveOne and Reciproc R25 instruments in artificial S-shaped canals. A study by De Deus et al. ${ }^{94}$ compared ProTaper Universal F2 instruments in forward reciprocating motion to continuous rotation, evaluating the cyclic fatigue resistance. The results show reciprocating movement to be better at reducing cyclic fatigue and extending the life of ProTaper Universal F2 instruments than continuous rotation. 
Reciprocating movement is able to prevent constant torque and continuous rotary force on the root canal wall, thus reducing dentinal damage. ${ }^{95}$ There are inconsistent results in the literature regarding the efficacy of bacterial reduction and debris removal. The possibility of dentinal crack formation and debris extrusion during endodontic treatment with reciprocating instruments remains. ${ }^{96}$

In a study by Gavini et al. ${ }^{97}$ a fatigue test was performed using the Reciproc R25 (VDW) in reciprocating motion and continuous rotation, with the instruments used in reciprocating motion taking longer to fracture. It took the instruments in the reciprocating group 357.56 seconds to fracture compared to the instruments in the continuous rotation group, which took 163.27 seconds. You et al. ${ }^{91}$ used a ProTaper Universal F2 instrument in reciprocating motion and a sequence of ProTaper Universal SX, S1, S2, F1 and F2 files in continuous rotation during the endodontic preparation of curved root canals of extracted molar teeth. The lifespan of the files was then analysed, with an extended lifespan being reported for the reciprocating motion ProTaper Universal F2 file.

A study by Kwak et al. ${ }^{98}$ comparing students' and novice operators' acceptance of rotary and reciprocating NiTi systems found a greater preference for reciprocating files than continuous rotation systems, and for NiTi files over stainless steel files.

A study by De Deus et al. ${ }^{99}$ concludes that there is no causal relationship between dentinal microcrack formation and canal preparations with WaveOne, BioRaCe (FKG Dentaire, La-Chaux-de-Fonds, Switzerland) and Reciproc (VDW) systems.

Wan et al. ${ }^{81}$ evaluated the cyclic fatigue resistance of four continuous rotation NiTi instruments, K3 (SybronEndo, Glendora, CA, USA), ProFile and GT Series $X$ (Dentsply Sirona), and a reciprocating instrument, SafeSider (Essential Dental Systems, South Hackensack, NJ, USA) in curved artificial canals. The results show that SafeSider files have a longer lifespan than the continuous rotation instruments. A similar study compared the cyclic fatigue resistance of WaveOne used with reciprocating motion to Twisted Files (SybronEndo) and ProTaper Universal files used in continuous rotation. The study found the WaveOne instrument to have a higher cyclic fatigue resistance as a result of the reciprocating motion. ${ }^{100}$

Rubini et al. ${ }^{101}$ evaluated the cyclic fatigue resistance of a size 40/04 HyFlex (Coltene/Whaledent AG, Altstatten, Switzerland) $\mathrm{NiTi}$ instrument used in both reciprocating motion and continuous rotation. The study found reciprocating motion improved cyclic fatigue resistance. Cunha et al. ${ }^{102}$ postulate that the low fracture incidence of WaveOne instruments may be attributed to the reciprocating motion, metallurgy and single-use nature of the file. They conclude that the incidence of file fracture when using the WaveOne reciprocating files is very low.

A study by Gambarini et al. ${ }^{23}$ compared the cyclic fatigue resistance between stainless steel K-Files used in a reciprocating motion and NiTi rotary PathFiles (Dentsply
Sirona) in artificial curved canals. The aim of their study was to evaluate whether stainless steel instruments could benefit from a reciprocating motion and $\mathrm{NiTi}$ rotary PathFile instruments, during enlargement of the glide path, given that reciprocation can improve the fatigue resistance of $\mathrm{NiTi}$ instruments. The stainless steel K-Files used with the M4 hand piece (SybronEndo) showed a significantly greater resistance to cyclic fatigue than the NiTi rotary PathFiles.

\section{Glide path}

A glide path is a smooth radicular tunnel extending from the canal orifice to the radiographic canal terminus or exit as determined by an electronic apex locator. ${ }^{103}$ The creation of a glide path ensures a patent canal permitting the safe and effective use of rotary instruments. ${ }^{104}$

The objective of a glide path in canal preparation is to produce a canal diameter which is the same size as, or a size bigger than, the first rotary instrument introduced. ${ }^{104,105}$

Peters ${ }^{106}$ and Roland et al. ${ }^{107}$ state that performing coronal enlargement of the root canal can reduce the risk of instrument fracture. In 2003, Blum et al. ${ }^{108}$ suggested the creation of a glide path with small flexible stainless steel hand files to ensure sufficient space for the introduction of rotary instruments. Berutti et al. ${ }^{104}$ recommend the preparation of a glide path by manual preflaring of the canal prior to using $\mathrm{NiTi}$ rotary instruments.

Various techniques and instruments have been advocated for the glide path preparation, such as manual preparation with stainless steel K-Files, a combination of stainless steel K-Files and a reciprocating hand piece, the use of a smaller tapered motor-driven NiTi rotary instrument or the use of hand files followed by rotary $\mathrm{NiTi}$ glide path files. ${ }^{72,109-111}$

In teeth with severely curved or constricted canals, using hand files has been shown to be more timeconsuming. ${ }^{112}$ A study in 2009 by Berutti et al. ${ }^{113}$ demonstrates that glide path preparation with hand files created unwanted modification of the canal curvature and more irregularities than did preparation with rotary PathFiles (Dentsply Sirona).

In 2013, Cassim and Van der Vyver ${ }^{114}$ concluded that rotary file systems performed better than stainless steel K-Files in a reciprocating hand piece, which in turn performed better than stainless-steel K-Files used by hand only. Once established, successful glide path preparation can reduce torsional stresses and increase the lifespan of a rotary instrument by up to six times, thereby reducing fracture risk and costs. ${ }^{104}$

Patiño et al. ${ }^{105}$ show that proper glide path preparation significantly reduces the incidence of instrument separation. A study by Vorster et al. ${ }^{115}$ shows that prior glide path preparation significantly reduces the final canal shaping time when the Primary WaveOne Gold file is used, compared to a group where no prior glide path was prepared before final canal shaping. 

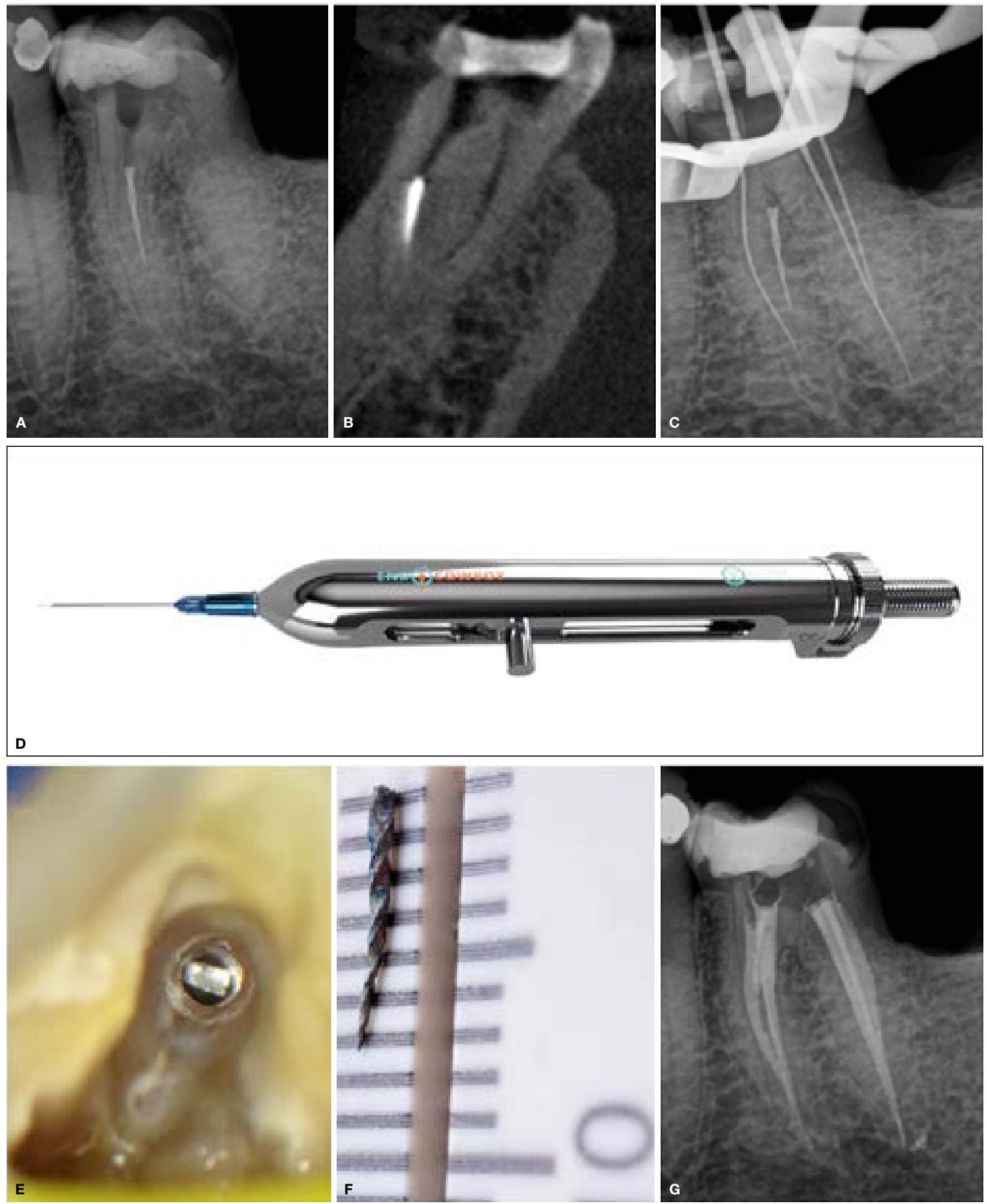

\section{Figure 3.}

A. Periapical radiograph showing a fractured instrument in the midroot area of the mesio-buccal root canal of a mandibular left first molar.

B. Sagittal view of a CBCT confirmed that the fragment was located just below the maximum curvature of the root canal system.

C. Length determination periapical radiograph confirming that the mesiolingual and mesio- and disto-buccal root canal systems were patent and could be negotiated to full working length.

D. EndoCowboy (Körhrer Medical Engineering), preloaded with the standard $0.12 \mathrm{~mm}$ wire in a $0.5 \mathrm{~mm}$ cannula.

E. Coronal aspect of fractured fragment in the mesio-buccal root canal system under $12 \mathrm{X}$ magnification.

F. Extracted fractured fragment measuring $6 \mathrm{~mm}$ on a ruler.

G. Postoperative periapical radiograph after root canal preparation and obturation of all the root canal systems. 
The preparation of a glide path prior to the introduction of a greater tapered instrument with a large tip diameter is advocated when using NiTi rotary instruments, as it reduces the occurrence of both types of fracture. ${ }^{116,117}$ The presence of a glide path allows the instrument to function under less torsional stress, with reduced risk of canal transportation. Glide path preparation with rotary instruments is faster, with less debris extrusion, than preparation with hand instruments. ${ }^{115,118,119}$

\section{CASE REPORT}

A 58-year-old male presented with a history of a fractured instrument in the mesio-buccal root canal of his mandibular left first molar. A periapical radiograph confirmed a fractured file located in the midroot region of the root (Figure 3a). A sagittal view of a cone beam computed tomography (CBCT) confirmed the location but demonstrated that the fragment was located just below the maximum curvature of the root canal system (Figure $3 \mathrm{~b}$ ). The mesio-lingual and mesio- and distobuccal root canal systems were patent and could be negotiated to full working length (Figure 3c).

It was decided to use the EndoCowboy (Körhrer Medical Engineering) to extract the fractured file from the root canal (Figure 3d). Figure 3e depicts the coronal aspect of fractured fragment in the mesio-buccal root canal system under $12 X$ magnification. A size 15 Endosonare file (Dentsply Sirona) mounted in a U-File holder (Endo Kit E12, NSK) driven by a Satelec P-5 ultrasonic Scaler (Satelec) was used to trough around and expose the coronal aspect of the fragment.

The EndoCowboy (Körhrer Medical Engineering), preloaded with the standard $0.12 \mathrm{~mm}$ wire in a $0.5 \mathrm{~mm}$ cannula, was introduced into the root canal, the preformed lasso was positioned around the separated instrument, the lasso closed and the fractured fragment (Figure 3f) extracted from the root canal using a pulling action. Figure $3 \mathrm{~g}$ shows the final obturation result after treatment of all the root canal systems.

\section{References}

1. Spili P, Parashos P, Messer HH. The Impact of Instrument Fracture on Outcome of Endodontic Treatment. J Endod. 2005; 31(12): 845-50.

2. Öztan M. Endodontic treatment of teeth associated with a large periapical lesion. Int Endod. J. 2002; 35(1): 73-8.

3. Soares JA, Brito-Júnior M, Silveira FF, Nunes E, Santos SM. Favorable response of an extensive periapical lesion to root canal treatment. J Oral Sci. 2008; 50(1): 107-11.

4. Al-Fouzan KS. Incidence of rotary ProFile instrument fracture and the potential for bypassing in vivo. Int Endod. J. 2003; 36(12): 864-7.

5. Schäfer E, Schulz-Bongert U, Tulus G. Comparison of Hand Stainless Steel and Nickel Titanium Rotary Instrumentation: A Clinical Study. J Endod. 2004; 30(6): 432-5.

6. Parashos P, Messer HH. Questionnaire survey on the use of rotary nickel-titanium endodontic instruments by Australian dentists. Int Endod J. 2004; 37(4): 249-59.

7. Zuolo ML, Walton RE. Instrument deterioration with usage: nickel-titanium versus stainless steel. Quintessence international 1997; 28(6): 397-402.
8. Parashos P, Gordon I, Messer HH. Factors influencing defects of rotary nickel-titanium endodontic instruments after clinical use. J Endod. Oct 2004; 30(10): 722-5.

9. Arens FC, Hoen MM, Steiman HR, Dietz GC Jr. Evaluation of single-use rotary nickel-titanium instruments. J Endod. 2003; 29(10): $664-6$.

10. Xu X, Eng M, Zheng $Y$, Eng D. Comparative Study of Torsional and Bending Properties for Six Models of NickelTitanium Root Canal Instruments with Different Cross-Sections. J Endod. 2006; 32(4): 372-5.

11. Berutti E, Chiandussi G, Gaviglio I, Ibba A. Comparative analysis of torsional and bending stresses in two mathematical models of nickel-titanium rotary instruments: ProTaper versus ProFile. J Endod. 2003; 29(1): 15-9.

12. Anusavice KJ. Phillips' Science of Dental Materials. $11^{\text {th }}$ ed. Philadelphia: Saunders; 2003.

13. Parashos P, Messer HH. Rotary NiTi Instrument Fracture and its Consequences. J Endod. 2006; 32(11): 1031-43.

14. McGuigan MB, Louca C, Duncan HF. Endodontic instrument fracture: causes and prevention. Br Dent J. 2013; 214(7): 341-8.

15. Sattapan B, Nervo GJ, Palamara JEA, Messer HH. Defects in Rotary Nickel-Titanium Files After Clinical Use. J Endod. 2000; 26(3): 161-5.

16. Cheung GSP, Peng B, Bian Z, Shen Y, Darvell BW. Defects in ProTaper $\mathrm{S} 1$ instruments after clinical use: fractographic examination. Int Endod J. 2005; 38(11): 802-9.

17. Shen Y, Cheung GS, Bian Z, Peng B. Comparison of Defects in ProFile and ProTaper Systems after Clinical Use. J Endod. 2006; 32(1): 61-5.

18. Bouska J, Justman B, Williamson A, DeLong C, Qian F. Resistance to Cyclic Fatigue Failure of a New Endodontic Rotary File. J Endod. 2012; 38(5): 667-9.

19. Zupanc J, Vahdat-Pajouh N, Schäfer E. New thermomechanically treated NiTi alloys - a review. Int Endod J. 2018; 51(10): 1088-103.

20. Algahtani $F$, Huang $X$, Haapasalo $M$, et al. Fatigue resistance of ProTaper gold exposed to high-concentration sodium hypochlorite in double curvature artificial canal. Bioactive Materials. 2019; 4: 245-8.

21. Boutsioukis C, Lambrianidis T. Factors Affecting Intracanal Instrument Fracture. Management of Fractured Endodontic Instruments: Springer; 2018: 31-60.

22. Kitchens GG, Jr., Liewehr FR, Moon PC. The effect of operational speed on the fracture of nickel-titanium rotary instruments. J Endod. 2007; 33(1): 52-4.

23. Gambarini G, Plotino G, Sannino G, et al. Cyclic fatigue of instruments for endodontic glide path. Odontology. 2015; 103(1): 56-60.

24. Grande NM, Plotino G, Pecci R, Bedini R, Malagnino VA, Somma F. Cyclic fatigue resistance and three-dimensional analysis of instruments from two nickel-titanium rotary systems. Int Endod J. 2006; 39(10): 755-63.

25. Pruett JP, Clement DJ, Carnes DL. Cyclic fatigue testing of nickel-titanium endodontic instruments. J Endod. 1997; 23(2): 77-85.

26. Setzer FC, Böhme CP. Influence of Combined Cyclic Fatigue and Torsional Stress on the Fracture Point of NickelTitanium Rotary Instruments. J Endod. 2013; 39(1): 133-7.

27. Gutmann JL, Gao Y. Alteration in the inherent metallic and surface properties of nickel-titanium root canal instruments to enhance performance, durability and safety: a focused review. Int Endod J. 2012; 45(2): 113-128.

28. Jonker $\mathrm{CH}$, De Wet FA, Van der Vyver PJ. The influence of glide path preparation on the failure rate of WaveOne reciprocating instruments: research. South African Dental Journal. 2014; 69(6): $266-9$.

29. Baek SH, Lee CJ, Versluis A, Kim BM, Lee W, Kim HC. Comparison of torsional stiffness of nickel-titanium rotary files with different geometric characteristics. J Endod. 2011; 37(9): 1283-6. 
30. Kim HC, Kwak SW, Cheung GS, Ko DH, Chung SM, Lee W. Cyclic fatigue and torsional resistance of two new nickeltitanium instruments used in reciprocation motion: Reciproc versus WaveOne. J Endod. 2012; 38(4): 541-4.

31. Zheng Q, Zhang L, Zhou X, et al. C-shaped root canal system in mandibular second molars in a Chinese population evaluated by cone-beam computed tomography. Int Endod J. 2011; 44(9): 857-62.

32. Cheung GSP, Zhang EW, Zheng YF. A numerical method for predicting the bending fatigue life of $\mathrm{NiTi}$ and stainless steel root canal instruments. Int Endod J. 2011; 44(4): 357-61.

33. Peters OA, de Azevedo Bahia MG, Pereira ESJ. Contemporary Root Canal Preparation: Innovations in Biomechanics. Dent Clin North Am. 2017; 61(1): 37-58.

34. Gambarini G, Plotino G, Grande NM, Al-Sudani D, De Luca M, Testarelli L. Mechanical properties of nickeltitanium rotary instruments produced with a new manufacturing technique. Int Endod J. 2011; 44(4): 337-41.

35. Johnson E, Lloyd A, Kuttler S, Namerow K. Comparison between a Novel Nickel-Titanium Alloy and 508 Nitinol on the Cyclic Fatigue Life of ProFile 25/.04 Rotary Instruments. J Endod. 2008; 34(11): 1406-9.

36. Shen Y, Tra C, Hieawy A, Wang Z, Haapasalo M. Effect of Torsional and Fatigue Preloading on HyFlex EDM Files. J Endod. 2018; 44(4): 643-7.

37. Alapati SB, Brantley WA, lijima M, et al. Metallurgical Characterization of a New Nickel-Titanium Wire for Rotary Endodontic Instruments. J Endod. 2009; 35(11): 1589 - 93

38. Ye J, Gao Y. Metallurgical Characterization of M-Wire Nickel-Titanium Shape Memory Alloy Used for Endodontic Rotary Instruments during Low-cycle Fatigue. J Endod. 2012; 38(1): 105-7.

39. Pereira ES, Peixoto IF, Viana AC, et al. Physical and mechanical properties of a thermomechanically treated NiTi wire used in the manufacture of rotary endodontic instruments. Int Endod J. 2012; 45(5): 469-74.

40. Alapati SB, Brantley WA, lijima M, et al. Metallurgical characterization of a new nickel-titanium wire for rotary endodontic instruments. J Endod. 2009; 35(11): 1589 - 93.

41. Bonessio N, Pereira ES, Lomiento G, et al. Validated finite element analyses of WaveOne Endodontic Instruments: a comparison between M-Wire and NiTi alloys. Int Endod J. 2015; 48(5): 441-50.

42. Pereira ESJ, Gomes RO, Leroy AMF, et al. Mechanical behavior of M-Wire and conventional $\mathrm{NiTi}$ wire used to manufacture rotary endodontic instruments. Dent Mater. 2013; 29(12): 318-24.

43. Acosta ECP, Resende PD, Peixoto IFdC, Pereira ÉSJ, Buono VTL, Bahia MGdA. Influence of cyclic flexural deformation on the torsional resistance of controlled memory and conventional nickel-titanium instruments. J Endod. 2017; 43(4): 613-8

44. Inojosa IDFDAJ, Lopes HP, Pereira PLR, et al. Fatigue resistance of endodontic instruments manufactured in NiTi $\mathrm{CM}$ Wire and in conventional NiTi alloy with eletrochemical treatment. 2018; 66(2): 111-6.

45. Braga LCM, Silva ACF, Buono VTL, de Azevedo Bahia MG. Impact of heat treatments on the fatigue resistance of different rotary nickel-titanium instruments. J Endod. 2014; 40(9): 1494-7.

46. Shen $Y$, Zhou H-mP, Zheng $Y$, Campbell L, Peng $B$, Haapasalo M. Metallurgical characterization of controlled memory wire nickel-titanium rotary instruments. J Endod. 2011; 37(11): 1566-71.

47. AlShwaimi E. Cyclic fatigue resistance of a novel rotary file manufactured using controlled memory $\mathrm{Ni}-\mathrm{Ti}$ technology compared to a file made from M-wire file. Int Endod $\mathrm{J}$. 2018; 51(1): 112-7.

48. Galal M. Metallurgical effect on the mechanical behavior of rotary endodontic files using finite element analysis. Bulletin of the National Research Centre. 2019; 43(1): 1-5.
49. Shen Y, Qian W, Abtin H, Gao Y, Haapasalo M. Fatigue testing of controlled memory wire nickel-titanium rotary instruments. J Endod. 2011; 37(7): 997-1001.

50. Adigüzel M, Capar ID. Comparison of Cyclic Fatigue Resistance of WaveOne and WaveOne Gold Small, Primary, and Large Instruments. J Endod. 2017; 43(4): 623-7.

51. Webber J. Shaping canals with confidence: WaveOne GOLD single-file reciprocating system. Roots International Magazine. 2015; 1: 28-33.

52. Elnaghy AM, Elsaka SE. Effect of sodium hypochlorite and saline on cyclic fatigue resistance of WaveOne Gold and Reciproc reciprocating instruments. Int Endod J. 2017; 50(10): 991-8

53. Yared G, Bou Dagher F, Machtou P. Influence of rotational speed, torque and operator's proficiency on ProFile failures. Int Endod J. 2001; 34(1): 47-53.

54. Yared G, Kulkarni G. Failure of ProFile Ni-Ti instruments used by an inexperienced operator under access limitations. Int Endod J. 2002; 35(6): 536-41.

55. Mesgouez C, Rilliard F, Matossian L, Nassiri K, Mandel E. Influence of operator experience on canal preparation time when using the rotary $\mathrm{Ni}-\mathrm{Ti}$ ProFile system in simulated curved canals. Int Endod J. 2003; 36(3): 161-5.

56. Mandel E, Adib-Yazdi M, Benhamou LM, Lachkar T, Mesgouez C, Sobel M. Rotary Ni-Ti profile systems for preparing curved canals in resin blocks: influence of operator on instrument breakage. Int Endod J. 1999; 32(6): 436-43.

57. Gambarini G. Cyclic fatigue of ProFile rotary instruments after prolonged clinical use. Int. Endod J. Jul 2001; 34(5): 386-9.

58. Yared GM, Dagher FE, Machtou P, Kulkarni GK. Influence of rotational speed, torque and operator proficiency on failure of Greater Taper files. Int Endod J. 2002; 35(1): 7-12.

59. Shen Y, Coil JM, McLean AGR, Hemerling DL, Haapasalo M. Defects in Nickel-Titanium Instruments after Clinical Use. Part 5: Single Use From Endodontic Specialty Practices. J Endod. 2009; 35(10): 1363-7.

60. Plotino G, Grande NM, Sorci E, Malagnino VA, Somma F. A comparison of cyclic fatigue between used and new M two Ni-Ti rotary instruments. Int Endod J. 2006; 39(9): 716-23.

61. Bahia MGA, Martins RC, Gonzalez BM, Buono VTL. Physical and mechanical characterization and the influence of cyclic loading on the behaviour of nickel-titanium wires employed in the manufacture of rotary endodontic instruments. Int Endod J. 2005; 38(11): 795-801.

62. Arens FC, Hoen MM, Steiman HR, Dietz GC, Jr. Evaluation of Single-use Rotary Nickel-titanium Instruments. J Endod. 2003; 29(10): 664-6.

63. Schneider K, Korkmaz YK, Addicks K, Lang H, Raab WHM. Prion protein (prp) in human teeth: An unprecedented pointer to prp's function. J Endod. 2007; 33(2): 110-3.

64. Gupta SK, Saxena P. Proposal for a simple and effective diagrammatic representation of root canal configuration for better communication amongst oral radiologists and clinicians. J Oral Biol Craniofac Res. 2016; 6(1): 59-65.

65. Wu J, Lei G, Yan M, Yu Y, Yu J, Zhang G. Instrument separation analysis of multi-used ProTaper Universal rotary system during root canal therapy. J Endod. 2011; 37(6): 758-63.

66. Plotino G, Grande NM, Mazza C, Petrovic R, Testarelli L, Gambarini G. Influence of size and taper of artificial canals on the trajectory of NiTi rotary instruments in cyclic fatigue studies. Oral surg, oral med, oral pathol, oral radiol, and endod. 2010; 109(1): 60-6.

67. Hülsmann M, Peters OA, Dummer PMH. Mechanical preparation of root canals: shaping goals, techniques and means. Endod Topics. 2005; 10(1): 30-76.

68. Prasad PS, Sam JE, Kumar A, Kannan. The effect of $5 \%$ sodium hypochlorite, $17 \%$ EDTA and triphala on two different rotary $\mathrm{Ni}-\mathrm{Ti}$ instruments: An AFM and EDS analysis. JCD. 2014; 17(5): 462-6. 
69. Dartar Oztan M, Akman AA, Zaimoglu L, Bilgiç S. Corrosion rates of stainless-steel files in different irrigating solutions. Int Endod J. 2002; 35(8): 655-9.

70. Yguel-Henry S, von Stebut J. Cutting efficiency loss of root canal instruments due to bulk plastic deformation, surface damage, and wear. J Endod. 1994; 20(8): 367-72.

71. Peters OA, Boessler C, Zehnder M. Effect of liquid and paste-type lubricants on torque values during simulated rotary root canal instrumentation. Int Endod J. 2005; 38(4): 223-9.

72. Berutti E, Angelini E, Rigolone M, Migliaretti G, Pasqualini D. Influence of sodium hypochlorite on fracture properties and corrosion of ProTaper Rotary instruments. Int Endod J. 2006; 39(9): 693-9.

73. Uslu G, Özyürek T, Yılmaz K, Plotino G. Effect of Dynamic Immersion in Sodium Hypochlorite and EDTA Solutions on Cyclic Fatigue Resistance of WaveOne and WaveOne Gold Reciprocating Nickel-titanium Files. J Endod. 2018; 44(5): 834-7.

74. Castellucci A, West JD. Endodontics Volume 2. $1^{\text {st }}$ édition Florence: Edizioni Odontoiatriche II Tridente. 2005.

75. Gambarini G. Rationale for the use of low-torque endodontic motors in root canal instrumentation. Dent. Traumatol. 2000; 16(3): 95-100.

76. Walia $\mathrm{H}$, Brantley WA, Gerstein $\mathrm{H}$. An initial investigation of the bending and torsional properties of nitinol root canal files. J Endod. 1988; 14(7): $346-51$

77. Hamid HR, Gluskin AH, Peters OA, Peters C. Rotary Versus Reciprocation Root Canal Preparation: Initial Clinical Quality Assessment in a Novice Clinician Cohort. J Endod. 2018; 44(8): 1257-62.

78. Gabel WP, Hoen M, Robert Steiman H, Pink FE, Dietz R. Effect of rotational speed on nickel-titanium file distortion. J Endod. 1999; 25(11): 752-4.

79. da Frota MF, Espir CG, Berbert FL, et al. Comparison of cyclic fatigue and torsional resistance in reciprocating single-file systems and continuous rotary instrumentation systems. J Oral Sci. 2014; 56(4): 269-75.

80. Grande NM, Ahmed HMA, Cohen S, Bukiet Fdr, Plotino GSUoRRI. Current Assessment of Reciprocation in Endodontic Preparation: A Comprehensive Review - Part I: Historic Perspectives and Current Applications. J Endod. 2015; 41(11): 1778-83.

81. Wan J, Rasimick BJ, Musikant BL, Deutsch AS. A comparison of cyclic fatigue resistance in reciprocating and rotary nickel-titanium instruments. Aus Endod J. 2011; 37(3): 122-7.

82. Pedullà E, Grande NM, Plotino G, Gambarini G, Rapisarda EDoESUoRRI. Influence of Continuous or Reciprocating Motion on Cyclic Fatigue Resistance of 4 Different NickelTitanium Rotary Instruments. J Endod. 2013; 39(2): 258-61.

83. Prabhakar AR, Yavagal C, Dixit K, Naik SV. Reciprocating vs. Rotary Instrumentation in Pediatric Endodontics: Cone Beam Computed Tomographic Analysis of Deciduous Root Canals using Two Single-file Systems. Int J Clin Pediatr Dent. 2016; 9(1): $45-9$

84. Yared G. Canal preparation using only one Ni-Ti rotary instrument: preliminary observations. Int Endod J. Apr 2008; 41(4): 339-44.

85. Shenouda M, Segari W, Zakhari S. Evaluation of deformation and fracture of three single-file NiTi rotary instruments: ProTaper F2, WaveOne Primary and OneShape in simulated curved canals. Journal of IMAB 2018; 24: 2014-s9.

86. Yılmaz K, Özyürek T, Uslu G. Comparision of Cyclic Fatigue Resistance of One Curve, Hyflex EDM, WaveOne Gold and Reciproc Blue Nickel-Titanium Rotary Files at Intra-canal Temperature. Cumhuriyet Dental Journal. 2019; 22: 42-7.

87. Best S, Watson P, Pilliar R, Kulkarni GGK, Yared G. Torsional fatigue and endurance limit of a size 30.06 ProFile rotary instrument. Int Endod J. 2004; 37(6): 370-3.
88. Pedullà E, Lo Savio F, Boninelli S, et al. Influence of cyclic torsional preloading on cyclic fatigue resistance of nickeltitanium instruments. Int Endod J. 2015; 48(11): 1043-50.

89. Bürklein S, Schäfer ECIAitSoDUoMnMnG. Apically Extruded Debris with Reciprocating Single-File and Full-sequence Rotary Instrumentation Systems. J Endod. 2012; 38(6): 850-2.

90. Rubio J, Zarzosa Jl, Pallarés A. A Comparative Study of Cyclic Fatigue of 10 Different Types of Endodontic Instruments: an in Vitro Study. 2019; 53(1): 28-36.

91. You SY, Bae KS, Baek SH, Kum KY, Shon WJ, Lee W. Lifespan of one nickel-titanium rotary file with reciprocating motion in curved root canals. J Endod. 2010; 36(12): 1991- 4.

92. Ferreira F, Adeodato C, Barbosa I, Aboud L, Scelza P, Zaccaro Scelza M. Movement kinematics and cyclic fatigue of NiTi rotary instruments: a systematic review. Int Endod J. Feb 2017; 50(2): 143-52.

93. Topçuoglu H, Düzgün S, Aktı A, Topçuoglu G. Laboratory comparison of cyclic fatigue resistance of WaveOne Gold, Reciproc and WaveOne files in canals with a double curvature. Int Endod J. 2017; 50(7): 713-7.

94. De-Deus G, Moreira EJL, Lopes HP, Elias CN. Extended cyclic fatigue life of F2 ProTaper instruments used in reciprocating movement. Int Endod J. 2010; 43(12): 1063-8.

95. Karatas E, Gunduz HA, Kirici DO, Arslan H, Topcu MC, Yeter KY. Dentinal crack formation during root canal preparations by the twisted file adaptive, ProTaper Next, ProTaper Universal, and WaveOne instruments. J Endod. 2015; 41(2): $261-4$

96. van der Vyver PJ, Jonker C. Reciprocating instruments in endodontics: a review of the literature. SADJ. 2014; 69(9): 404-9.

97. Gavini G, Caldeira CL, Akisue E, Candeiro GTDM, Kawakami DAS. Resistance to Flexural Fatigue of Reciproc R25 Files under Continuous Rotation and Reciprocating Movement. J Endod. 2012; 38(5): 684 -7.

98. Kwak SW, Cheung GS, Ha JH, Kim SK, Lee H, Kim HC. Preference of undergraduate students after first experience on nickel-titanium endodontic instruments. Restorative dentistry \& endodontics. 2016; 41(3): $176-181$.

99. De-Deus G, Silva EJ, Marins J, et al. Lack of causal relationship between dentinal microcracks and root canal preparation with reciprocation systems. J Endod. 2014; 40(9): 1447-50.

100.Castello-Escriva R, Alegre-Domingo T, Faus-Matoses V, Roman-Richon S, Faus-Llacer VJ. In vitro comparison of cyclic fatigue resistance of ProTaper, WaveOne, and Twisted Files. J Endod. 2012; 38(11): 1521-4.

101. Rubini AG, Sannino G, Pongione G, et al. Influence of file motion on cyclic fatigue of new nickel titanium instruments. Ann Stomatol (Roma). 2013; 4(1): 149-51.

102. Cunha RS, Junaid A, Ensinas P, Nudera W, Bueno CE. Assessment of the separation incidence of reciprocating WaveOne files: a prospective clinical study. J Endod 2014; 40(7): 922-4.

103. West J. Endodontic Update 2006. JERD. 2006; 18(5): 280300.

104. Berutti E, Negro AR, Lendini M, Pasqualini D. Influence of manual preflaring and torque on the failure rate of ProTaper rotary instruments. J Endod. 2004; 30(4): 228-30.

105.Patiño PV, Biedma BM, Liébana CR, Cantatore G, Bahillo JG. The Influence of a Manual Glide Path on the Separation Rate of NiTi Rotary Instruments. J Endod. 2005; 31(2): 114-6.

106. Peters OA. Current Challenges and Concepts in the Preparation of Root Canal Systems: A Review. J Endod. 2004; 30(8): $559-67$. 
107. Roland DD, Andelin WE, Browning DF, Hsu GH, Torabinejad $M$. The effect of preflaring on the rates of separation for 0.04 taper nickel titanium rotary instruments. J Endod. 2002; 28(7): 543 - 5.

108. Blum JY, Machtou P, Ruddle C, Micallef JP. Analysis of mechanical preparations in extracted teeth using ProTaper rotary instruments: value of the safety quotient. J Endod. 2003; 29(9): 567-75.

109. Nakagawa RKL, Alves JL, Buono VTL, Bahia MGA. Flexibility and torsional behaviour of rotary nickel-titanium PathFile, RaCe ISO 10, Scout RaCe and stainless steel K-File hand instruments. Int Endod J. 2014; 47(3): 290 - 7.

110. Walsch $\mathrm{H}$. The hybrid concept of nickel-titanium rotary instrumentation. Vol 482004.

111. Gianluca G. The K3 rotary nickel titanium instrument system. Endodontic Topics. 2005; 10(1): 179-82.

112. D'Amario M, Baldi M, Petricca R, De Angelis F, El Abed R, D'Arcangelo C. Evaluation of a new nickel-titanium system to create the glide path in root canal preparation of curved canals. J Endod. 2013; 39(12): 1581- 4.

113. Berutti E, Cantatore G, Castellucci A, et al. Use of nickeltitanium rotary PathFile to create the glide path: comparison with manual preflaring in simulated root canals. J Endod. 2009; 35(3): 408-12.
114. Cassim I, Van der Vyver P. An in vitro comparison of different techniques for glide path preparation. SADJ. 2015; 70(10): 452-6.

115. Vorster M, van der Vyver PJ, Paleker F. Influence of Glide Path Preparation on the Canal Shaping Times of WaveOne Gold in Curved Mandibular Molar Canals. J Endod. 2018; 44(5): 853-5.

116. Ruddle CJ, Machtou P, West JD. Endodontic canal preparation: innovations in glide path management and shaping canals. Dent Today. 2014; 33(7): 118-23.

117. West JD. The endodontic Glidepath: "Secret to rotary safety". Dent Today. 2010; 29(9): 86,88,90-3.

118. Cheung GSP, Liu CSY. A Retrospective Study of Endodontic Treatment Outcome between Nickel-Titanium Rotary and Stainless Steel Hand Filing Techniques. J Endod. 2009; 35(7): 938-43.

119. Paleker F, van der Vyver PJ. Comparison of Canal Transportation and Centering Ability of K-files, ProGlider File, and G-Files: A Micro-Computed Tomography Study of Curved Root Canals. J Endod. 2016; 42(7): 1105-9.

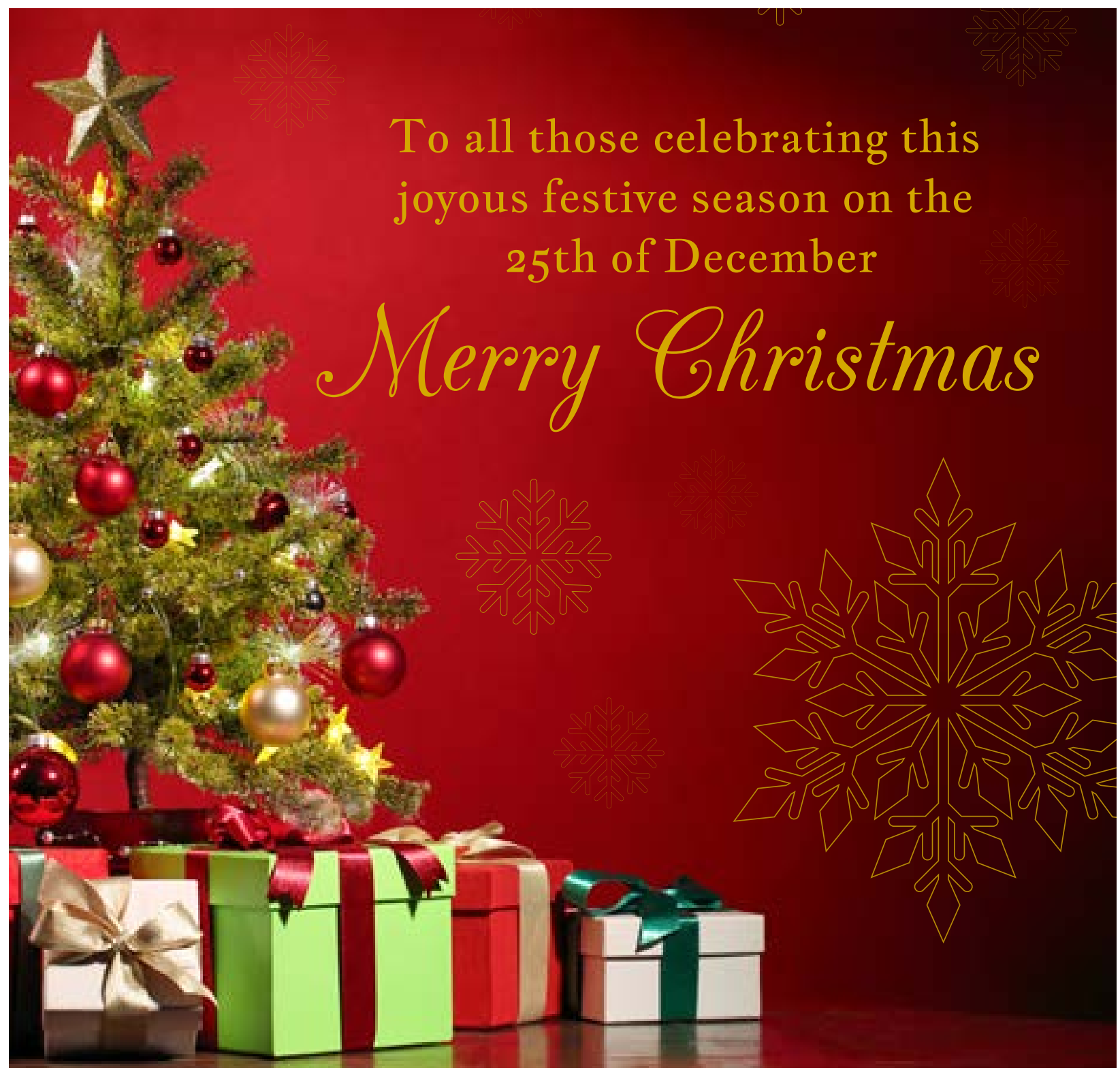

